\title{
Geoespaço: um material manipulativo para o planejamento de tarefas de representação figural no Ensino Médio
}

Geospatial: a manipulative material for the planning of tasks of figural representation in High School

\author{
Luiz Rodolfo Kusuki* \\ Paulo Cesar Oliveira*
}

\section{Resumo}

O texto é uma síntese da dissertação de mestrado defendida pelo primeiro autor, sob a orientação do segundo autor, pelo Programa de Pós-Graduação em Ensino de Ciências Exatas (PPGECE) da Universidade Federal de São Carlos. O objetivo do artigo consiste em apresentar a construção do material manipulativo Geoespaço, o planejamento e desenvolvimento de representação figural em uma turma de alunos de terceira série do Ensino Médio. A fundamentação teórica levou em conta a apropriação da concepção de material manipulativo defendida por Lorenzato (2006) e as contribuições da teoria das representações figurais de Fischbein (1993). Com base em uma pesquisa de natureza qualitativa, a produção das atividades matemáticas dos alunos foram analisadas mediante às seguintes categorias: conceito figural e vocabulário adequado de termos geométricos. Finalizamos a redação do nosso texto apresentando reflexões sobre o papel do professor-pesquisador no contexto do uso de materiais manipulativos em sala de aula.

Palavras-chave: Geoespaço. Ensino-aprendizagem. Geometria. Ensino Médio. Material manipulativo.

\section{Abstract}

The text is a synthesis of the master's dissertation defended by the first author, under the guidance of the second author, by the Post-Graduate Program in Teaching of Exact Sciences (PPGECE) of the Federal University of São Carlos. The objective of the article is to present the construction of the manipulative material Geospace, the planning and development of figural representation in a class of third year high school students. The theoretical foundation took into account the appropriation of the conception of manipulative material defended by Lorenzato (2006) and the contributions of Fischbein's theory of representations (1993). Based on qualitative research, the students' mathematical activities were analyzed using the following categories: figural concept and adequate vocabulary of geometric terms. We finished the writing of our text presenting

\footnotetext{
* Luiz Rodolfo Kusuki, Mestre no Ensino de Ciências Exatas (PPGECE - UFSCar) e docente na Universidade de Sorocaba (UNISO). E-mail: luizrodolfo@outlook.com

* Paulo César Oliveira, Doutor em Educação Matemática, Docente do programa de PósGraduação em Ensino de Ciências Exatas da Universidade Federal de São Carlos, e-mail: paulooliveira@ufscar.br
} 
reflections on the role of teacher-researcher in the context of the use of manipulative materials in the classroom.

Keywords: Geospatial. Teaching-learning. Geometry. High school. Manipulative material.

\section{Introdução}

O desenvolvimento da dissertação de mestrado por Kusuki (2014) buscou responder a seguinte questão de pesquisa: que aprendizagem ocorre com conteúdos de geometria espacial via Geoespaço, em um contexto de tarefas exploratórias-investigativas?

A escolha do Geoespaço como objeto dessa pesquisa se deu pelo fato não ter encontrado nenhum trabalho acadêmico na modalidade de dissertação ou tese no Brasil sobre o mesmo, apesar da montante de trabalhos encontrados sobre 0 uso do Geoplano, que tem a mesma finalidade, mas voltado para o ensino da geometria plana.

Durante as aulas ministradas por Kusuki (2014) envolvendo conteúdos de geometria espacial em escolas públicas da rede estadual do estado de São Paulo, foi possível constatar que tanto no Ensino Fundamental II, quanto no Ensino Médio, os alunos não conseguiam identificar as propriedades das figuras espaciais, não compreendendo as representações apresentadas nos livros didáticos disponíveis.

Essa dificuldade de abstrair e imaginar os sólidos geométricos (prismas, pirâmides, cones e cilindros) ocorreu pelo fato de a geometria ser uma área da matemática que exige a experimentação por intermédio de atividades concretas, cuja análise de modelos matemáticos faz referência a situações reais. Tal análise só pode ser feita de modo satisfatório se os envolvidos nela compreenderem tal referência, fato que ocorre através da manipulação de "objetos matemáticos" concretos que auxiliam na compreensão e abstração por parte dos alunos.

Visando romper essa barreira, foi escolhido o Geoespaço, por se tratar de um material didático manipulativo, a partir do qual é possível construir e analisar tais objetos matemáticos, sendo que os mesmos não são estáticos, podendo ser 
alterados de acordo com as necessidades e permitindo construções que ajudam na visualização de propriedades como: diagonais, alturas, apótemas, raios e diâmetros entre outros.

\section{Apresentação do Produto Educacional}

O Geoespaço é um dos recursos que pode auxiliar no trabalho da geometria espacial, desenvolvendo atividades que envolvam a análise de sólidos geométricos. Trata-se de um material didático manipulativo (experimental ou demonstrativo) de uso do professor e também do aluno, que pode ser confeccionado pelo próprio professor. A vantagem de ser confeccionado é que o professor pode construí-lo conforme a necessidade. É um material de uso individual ou em grupo, que pode ser utilizado tanto para a indução quanto para a dedução de conceitos de geometria espacial.

O primeiro contato com o Geoespaço foi através do livro "O laboratório de ensino de matemática na formação de professores" de Lorenzato (2006), no qual ele expõe um Geoespaço desenvolvido no Laboratório de Estudos e Pesquisa da Aprendizagem Cientifica (LEPAC), vinculado ao departamento de Matemática do Centro de Ciências Exatas e da Natureza da Universidade Federal da Paraíba (CCEN/UFPB) como mostra a figura 1.

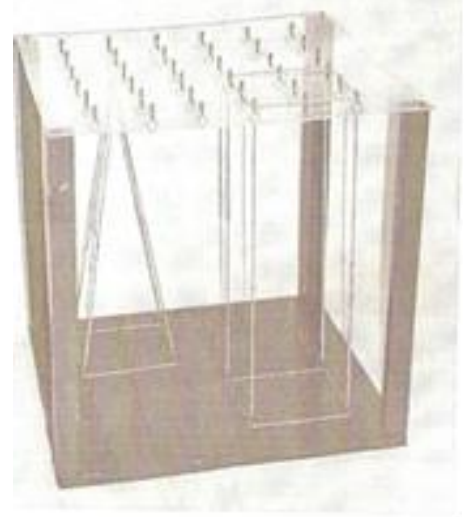

FIGURA 1: Geoespaço desenvolvido no LEPAC

Fonte: Lorenzato (2006)

A partir deste modelo, foram desenvolvidos junto ao Grupo de Estudos e Planejamento de Aulas de Matemática (GEPLAM), vinculado ao Programa de 
Pós-Graduação em Ensino de Ciências Exatas (PPGECE) da Universidade Federal de São Carlos (UFSCar-Campus de Sorocaba) sob a liderança do segundo autor deste artigo, dois tipos de Geoespaço: quadrangular e circular.

\subsection{Geoespaço Quadrangular}

Semelhante ao Geoespaço construído pelo LEPAC, esse é formado por duas placas quadradas de madeira de $40 \mathrm{~cm}$ de lado, quatro cabos cilíndricos de madeira com $45 \mathrm{~cm}$ cada, 170 pequenos ganchos de cobre e elásticos de diversas cores, 8 parafusos para madeira e 2 pés para móveis de borracha como mostramos a seguir:

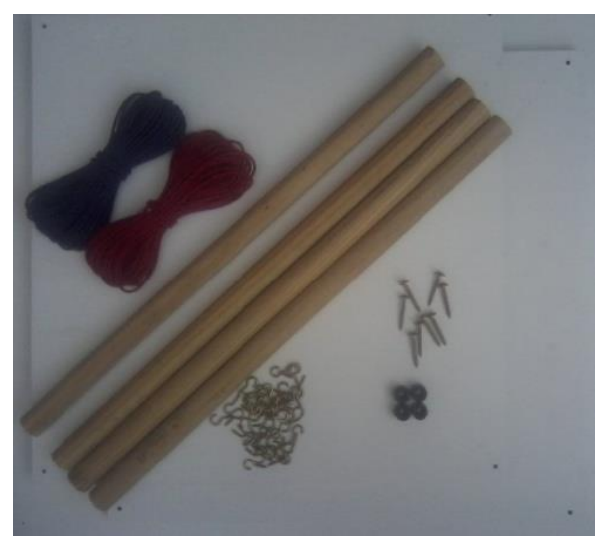

FIGURA 2: Componentes do Geoespaço quadrangular Fonte: arquivo do pesquisador

No Geoespaço quadrangular as duas bases de madeira são desenhadas malhas quadriculadas com $32 \mathrm{~cm}$ de lado, sendo que cada quadrado tem $4 \mathrm{~cm}$ de lado. Em seguida são feitos furos em todos os cantos dos quadrados da malha $\mathrm{e}$ neles são afixados os ganchos de cobre:

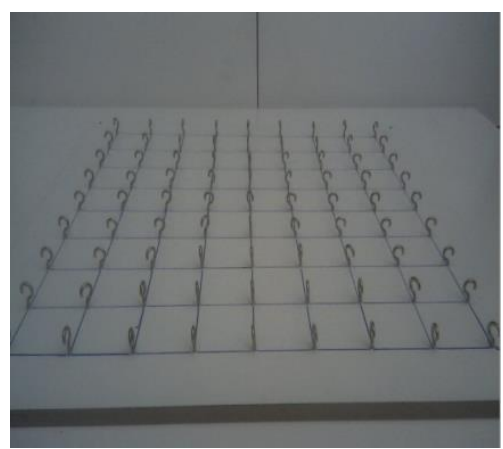

FIGURA 3: Malha e ganchos 
Fonte: arquivo do pesquisador

Feito isso, as bases são parafusadas nos quatro cabos de madeira formando assim o Geoespaço quadrangular, conforme ilustração a seguir:

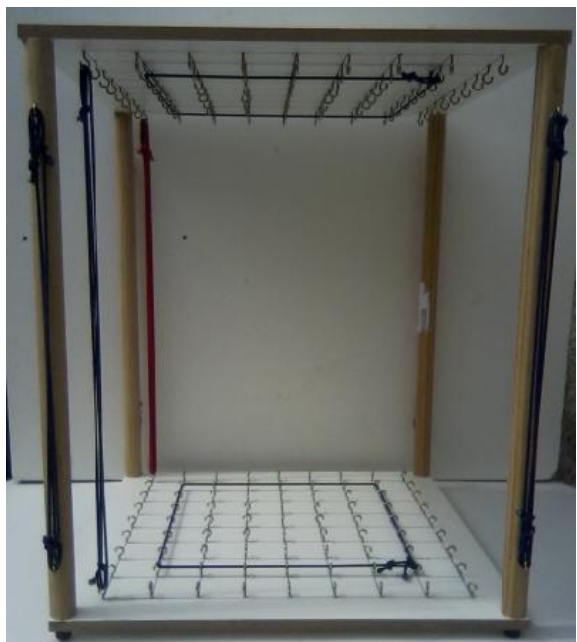

FIGURA 4: Geoespaço Quadrangular

Fonte: arquivo do pesquisador

Nesse Geoespaço é possível fazer a representação de prismas e pirâmides de diversas bases, sendo elas retas ou obliquas. A partir da representação de um prisma nesse material didático manipulativo é possível determinar o número de arestas, vértices e faces do prisma, calcular a área lateral e a área da base, calcular o comprimento de uma diagonal da face ou o comprimento de uma diagonal do prisma, calcular o volume do prisma.

A partir da representação de uma pirâmide no Geoespaço quadrangular é possível determinar o número de arestas, vértices e faces, visualizar a altura da pirâmide, calcular a área lateral, a área da base e o volume da pirâmide. É possível construir também o tronco de uma pirâmide, uma pirâmide inscrita em um prisma de mesma base, bem como representar a relação entre o volume da pirâmide e do prisma.

\subsection{Geoespaço Circular}

Esse Geoespaço foi desenvolvido junto ao GEPLAM, ao serem levantadas questões sobre o trabalho com cilindros e cones e se poderia ser construído um material similar ao Geoespaço quadrangular, mas que fizesse um estudo das 
propriedades do cilindro e do cone. Não foram encontradas referências sobre a existência do mesmo, portanto, sua construção tomou por base a construção do Geoplano circular.

O kit Geoespaço circular é formado por duas placas quadradas de madeira de $40 \mathrm{~cm}$ de lado, quatro cabos cilíndricos de madeira com $45 \mathrm{~cm}$ cada, 240 pequenos ganchos de cobre e elásticos de diversas cores, 8 parafusos para madeira e 4 pés para móveis de borracha. Nas duas bases de madeira são desenhados círculos concêntricos de raios $6 \mathrm{~cm}, 8,5 \mathrm{~cm}, 10 \mathrm{~cm}, 11,5$ e $14 \mathrm{~cm}$. A escolha destas medidas foi de acordo com objetos circulares disponíveis durante a construção. Na sequência são feitos os furos nas circunferências em um intervalo de $15^{\circ}$ e um furo central, onde são afixados os ganchos de cobre:

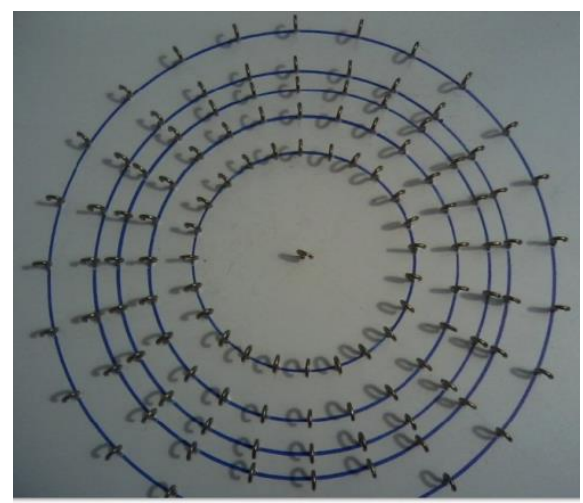

FIGURA 5: Círculos e ganchos

Fonte: arquivo do pesquisador

Feito isto, as bases são parafusadas nos quatro cabos de madeira formando assim o Geoespaço circular: 


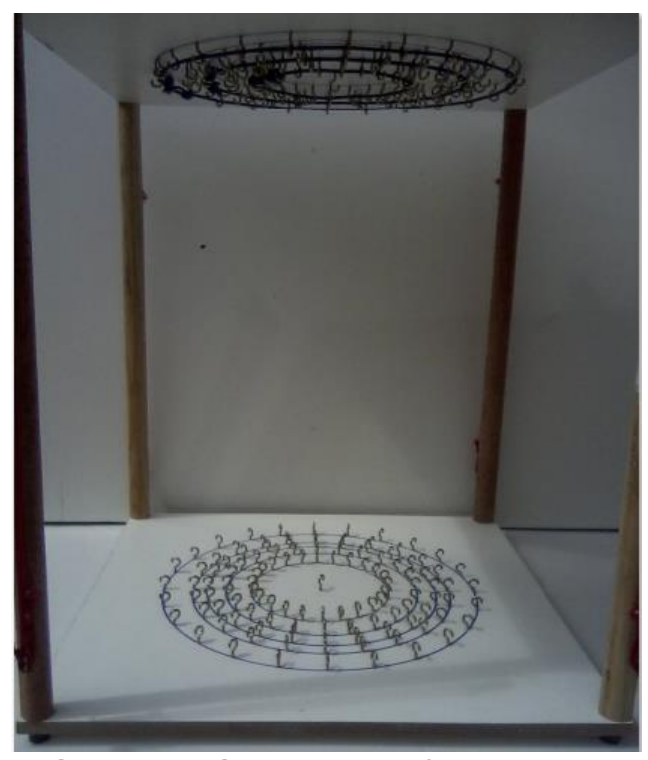

FIGURA 6: Geoespaço Circular

Fonte: arquivo do pesquisador

Nesse Geoespaço é possível fazer a representação de cilindros e cones retos ou oblíquos. A partir da representação do cilindro é possível visualizar o raio da base, a altura do cilindro, a secção meridiana, calcular sua área lateral, sua área da base e seu volume. Já na representação de um cone é possível visualizar o raio da base, a altura do cone, a geratriz do cone, a secção meridiana, calcular a área da base, a área lateral e o volume.

Sendo possível construir um tronco de cone e um cone inscrito em um cilindro de mesma base, podemos calcular o volume do tronco do cone e a relação entre o volume do cilindro e do cone. Outra tarefa que pode ser construída a partir do Geoespaço circular é a visualização e cálculo do volume de uma secção do cone ou cilindro a partir do centro de sua base, como o cálculo do volume de $1 / 4$ do cilindro.

\subsection{0 processo de experimentação com o Geoespaço}

No Currículo do Estado de São Paulo (SÃO PAULO, 2012), a geometria métrica espacial é trabalhada de maneira mais aprofundada no $4^{\circ}$ bimestre da $2^{\underline{a}}$ série do ensino médio. Os conteúdos a serem trabalhados são: elementos da geometria de posição; poliedros, prismas e pirâmides, cilindros e cones. Quanto 
às habilidades e competências a serem atingidas com base neste documento, 0 aluno deve compreender os fatos fundamentais relativos ao modo geométrico de organização do conhecimento (conceitos primitivos, definições, postulados e teoremas), identificar propriedades características, calcular relações métricas fundamentais (comprimentos, áreas e volumes) de sólidos como o prisma e o cilindro, utilizando-as em diferentes contextos.

Para o desenvolvimento do trabalho de campo da dissertação de Kusuki (2014), foi escolhida uma turma de 20 alunos da $3^{\text {a }}$ Série do ensino médio, de uma escola da rede estadual do município de Sorocaba - SP, pelo fato deles já terem estudado toda a parte de geometria espacial no final da série anterior. $O$ primeiro contato desse professor-pesquisador com a referida turma ocorreu no inicio do ano letivo de 2013.

Essa turma de alunos era de responsabilidade do próprio pesquisador devido à atribuição de aulas. Durante o primeiro semestre letivo de 2013, antes de abordarmos o conteúdo programático previsto para a $3^{\text {a }}$ série do Ensino Médio (geometria analítica), de acordo com o Currículo do Estado de São Paulo (SÃO PAULO, 2012), foi feita uma revisão referente aos conteúdos da geometria plana e espacial. Tal revisão teve como objetivo diagnosticar as competências e habilidades adquiridas durante as duas primeiras séries do ensino médio.

No que diz respeito à geometria espacial (foco desse estudo) foi constatado que os alunos sabiam calcular as relações métricas fundamentais (comprimentos, áreas e volumes) de sólidos como o prisma e o cilindro, utilizando-as em diferentes contextos. Sabiam compreender os fatos fundamentais relativos ao modo geométrico de organização do conhecimento (conceitos primitivos, definições, postulados e teoremas) diferenciando sólidos como prismas, pirâmides, cilindros e cones, mas tinham muita dificuldade de identificar propriedades características com as representações geométricas dos mesmos. Não conseguiram compreender a representação figural de um sólido geométrico através de sua representação em duas dimensões (figura estática exposta a seguir), não diferenciando e identificando conceitos elementares como 
vértices, arestas, faces, altura, comprimento e largura, raio da base (cilindro e cone), diâmetro da base (cilindro e cone), diagonais internas, entre outros.

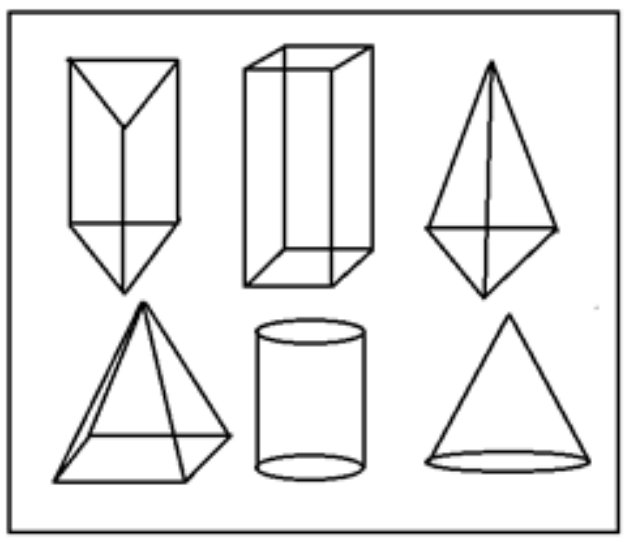

FIGURA 7: Figura estática

Fonte: arquivo do pesquisador

Estas limitações na aprendizagem desses alunos foram motivadoras no planejamento e aplicação de tarefas com o uso do material manipulável Geoespaço. Portanto, nossa pesquisa envolveu a presença do cotidiano de uma sala de aula na qual o professor também exerceu a função de pesquisador na construção de saberes com os seus alunos. Neste contexto, a abordagem de pesquisa adequada foi a qualitativa, uma vez que Moreira (2018) chama-nos a atenção de que a segurança das compreensões obtidas nas investigações qualitativas radica-se no pesquisador e no diálogo pesquisador/comunidade.

A produção das informações no cenário de sala de aula ocorreu em dois momentos distintos. Primeiramente, foi elaborada uma série de tarefas com o objetivo de fazer uma análise da representação dos objetos geométricos tridimensionais, a partir dos registros escritos das atividades matemáticas dos alunos. Consequentemente, proporcionamos aos alunos a possibilidade de construção dos sólidos geométricos para que pudessem aprender os referidos conceitos elementares com os quais não estavam familiarizados. Posteriormente, planejamos e aplicamos tarefas de natureza exploratório-investigativa visando uma aprendizagem em que o aluno pudesse ser capaz de associar o número de arestas, faces e vértices de modo a construir a relação de Euler. 
Na fase de elaboração e aplicação das tarefas relativas à representação do objeto tridimensional, identificamos a categoria conceito figural na perspectiva de Fischbein (1993), para a análise da produção de informações dos alunos. Posteriormente, durante um encontro entre orientador e orientando para a avaliação preliminar das atividades matemáticas dos alunos, identificamos, a partir da leitura dos registros escritos, outra categoria de análise: uso adequado de termos geométricos, interpretado como vocabulário empregado pelos dos alunos na resolução das tarefas.

O segundo momento do nosso trabalho de campo (construção da relação de Euler) contou com o desenvolvimento e aplicação de tarefas exploratórioinvestigativas que teve a análise da produção de informações, com base em Ponte (2009), do processo de formulação de conjecturas a partir da organização dos dados, a realização de testes e eventual refinamento das conjecturas, fazendo afirmações sobre as mesmas e argumentação, demonstração e avaliação do trabalho realizado. Para esta fase do trabalho de campo, adotamos a seguinte categoria de análise: generalidade e abstração dos conceitos sob a perspectiva de Pais (1996).

A escolha de tarefas exploratório-investigativas teve influência de Grando, Nacarato e Gonçalves (2008), que considera que esse recurso pedagógico pode minimizar algumas "lacunas" existentes, decorrentes do pouco ensino de conteúdos geométricos na educação básica. De acordo com estas autoras, como as tarefas são abertas, se o aluno tiver o domínio restrito dos conteúdos geométricos, muito provavelmente a tarefa permaneça no nível da exploração, mas se esta também estiver voltada para o domínio de conteúdos algébricos, existe grande possibilidade de se tornar investigativa.

Nas próximas seções dedicamos à exposição de cada aporte teórico com o respectivo planejamento, aplicação e análise das tarefas com os referidos alunos da 3ª série do Ensino Médio. 


\section{Representação figural, generalização e abstração de conceitos}

Em relação à teoria dos conceitos figurais, categoria de análise da produção de informações da primeira etapa de tarefas, esta se refere à representação sensorial de um objeto ou fenômeno. Uma vez que os objetos materiais (sólidos ou desenho) são apenas modelos materializados das entidades mentais com as quais lidam o matemático, apenas num senso conceitual podemos considerar a perfeição absoluta das entidades geométricas. Tais entidades não possuem correspondentes matemáticos verdadeiros e a figura geométrica é descrita como tendo intrinsecamente propriedades conceituais.

Para Fischbein (1993) os objetos de investigação e manipulação do pensamento geométrico são então entidades mentais denominadas conceitos figurais, que exprimem propriedades espaciais como forma, espaço e magnitude bem como possuem qualidades conceituais como idealidade, abstração, universalidade e perfeição. As imagens mentais das figuras geométricas podem ser baseadas na experiência perceptiva sensorial, na imagem de um desenho ou na definição formal.

Para Fischbein (1993), o controle conceitual deve ser intrínseco, ou seja, é inerente ao processo de ensino-aprendizagem, e a imagem e o conceito devem fundir-se em um objeto mental único, sendo que o conceito é o fato que expressa uma ideia, representação ideal de uma classe de objetos, baseada em seus aspectos comuns e uma imagem (imagens mentais) é uma representação sensorial de um objeto ou fenômeno, o que faz com que o desenvolvimento de conceitos figurais não ocorra de maneira natural.

Em raciocínio matemático não nos referimos a uma representação figural como objetos materiais ou desenhos. Os objetos materiais (sólidos ou desenhos) são somente modelos materializados das entidades mentais com as quais o matemático lida. Somente num senso conceitual podemos considerar a perfeição absoluta das entidades geométricas: linhas retas, círculos, quadrados, cubos, entre outros. 
Essas entidades geométricas não possuem correspondentes materiais verdadeiros. Pontos, linhas e planos não existem, não podem existir na realidade. Os objetos reais na nossa experiência prática são necessariamente tridimensionais, mas mesmo o cubo ao qual o matemático se refere, não existe na realidade. Embora seja tridimensional, esse também é uma imagem mental que não deve possuir qualquer realidade substancial, seja qual for.

Todas essas construções são representações universais, como cada conceito, e nunca cópias mentais particulares de objetos concretos. Quando você desenha uma figura geométrica numa folha de papel para checar algumas de suas propriedades, você não se refere ao respectivo desenho particular, mas ao formato de uma infinita classe de objetos. Mesmo o formato particular desenhado por você, com seus lados e ângulos pode ser o formato de uma infinidade de objetos. Na verdade, nós lidamos com uma hierarquia de formatos, de um aparentemente particular, mas de fato correspondente a uma infinidade de objetos possíveis, à categoria universal da figura geométrica desenhada. Idealidade, abstração, perfeição absoluta e universalidade são propriedades que fazem sentido no domínio dos conceitos.

As figuras geométricas também podem ser relacionadas à sua natureza conceitual. As propriedades das figuras geométricas são impostas ou derivadas de definições no reino de certo sistema evidente. Também desse ponto de vista, uma figura geométrica tem natureza conceitual. Um quadrado não é uma imagem desenhada numa folha de papel. É um formato controlado por sua definição (embora possa ser inspirado por um objeto real). Um quadrado é um retângulo que possui lados iguais. Começando dessas propriedades, podemos prosseguir para descobrir outras propriedades do quadrado (a igualdade de ângulos que são todos ângulos retos, a igualdade de diagonais, entre outros).

Uma figura geométrica pode então ser descrita como tendo propriedades conceituais. Todavia, uma figura geométrica não é um mero conceito, é uma imagem visual e possui uma propriedade que conceitos usuais não possuem, a saber, inclui a representação mental da propriedade espaço. 
Da mesma forma quando conceituamos, por exemplo, um sólido no Geoespaço para descrever sua tridimensionalidade, não somente a imagem do sólido é associada a isso, mas também um terceiro tipo de construção que é a figura geométrica que representa esse sólido.

Se vamos resolver uma tarefa na qual temos que calcular, por exemplo, a distância percorrida entre dois vértices, sabendo a medida das arestas do sólido, o cálculo é feito considerando um modelo abstrato do sólido que não é nem uma imagem pura nem um conceito puro. Conceitos são vértices, não se movem e imagens não possuem perfeição, universalidade, abstração e a pureza que supomos enquanto realizamos os cálculos.

Quando nós imaginamos um sólido, imaginamos um sólido desenhado (incluindo, por exemplo, a cor da tinta) e não o ideal sólido perfeito. Mas um objeto matemático, que é o objeto do nosso raciocínio matemático, não tem cor, substância, massa, entre outros e é, supostamente, idealmente perfeito. Possui todas as propriedades de um conceito e pode fazer parte do raciocínio matemático, a despeito do fato de que ainda inclui a representação de propriedades espaciais.

Para Fischbein (1993), os objetos de investigação e manipulação no pensamento geométrico são então entidades mentais, a que chamamos conceitos figurais, o que exprime propriedades espaciais (forma, posição, magnitude) e, ao mesmo tempo, possuem qualidades conceituais como idealidade, abstração, universalidade e perfeição,

A ideia do uso do Geoespaço segundo essa teoria é analisar por meio da manipulação do mesmo, as propriedades espaciais e o modo como cada aluno desenvolve as entidades mentais dos conceitos figurais, fazendo uma relação entre as representações figurais obtidas pelos alunos e as fornecidas pelos livros.

Em relação a generalidade e a abstração dos conceitos, pautada em Pais (1996), elas são construídas pouco a pouco, em um processo dialético que envolve necessariamente a influência do mundo físico e uma reflexão sobre ele. Estabelece-se uma relação de comparação permanente entre o mundo das ideias 
e o mundo físico sendo que, durante o processo de conceitualização, o aluno lança mão dos recursos concretos, entrando em cena as representações por objetos e desenhos e, posteriormente pelas representações mentais.

Em relação ao estudo a partir do concreto, Nacarato (2005) afirma que, no caso da geometria, materiais didáticos como o Geoespaço são fundamentais em todas as séries e níveis de ensino, uma vez que podem contribuir para o desenvolvimento da visualização.

\subsection{Tarefas de representação figural}

O planejamento e desenvolvimento de tarefas visando a representação figural dos sólidos geométricos envolveram prisma, pirâmide, cilindro e cone.

As tarefas de representação figural foram desenvolvidas em dois encontros, cada um com duas horas-aulas. No primeiro encontro o Geoespaço foi apresentado aos alunos, sendo realizadas as tarefas referentes à representação figural dos prismas e, no segundo encontro, os alunos realizaram as tarefas referentes à representação figural das pirâmides, do cilindro e do cone.

Em cada tarefa foram construídos os sólidos no Geoespaço pelos alunos com o auxilio do professor. Feita essa construção, cada aluno tinha que fazer uma representação figural do sólido construído em uma folha de papel. Após todos os alunos realizarem essa representação, o professor-pesquisador apresentou o desenho do sólido abordado contido no livro didático de matemática (DANTE, 2010), o qual estava sendo utilizado em todas as séries do Ensino Médio da unidade escolar em que ocorreu o trabalho de campo dessa pesquisa.

$\mathrm{Na}$ sequencia, os alunos comparam a representação figural do sólido com o desenho fornecido no livro didático e responderam algumas questões sobre essa relação.

Como forma de detalhar a utilização do produto educacional, apresentamos uma descrição quantitativa e uma análise qualitativa dos resultados obtidos no desenvolvimento da tarefa, tomando por base o cone, dada a limitação e escopo do artigo. 


\subsubsection{Representação 3D/2D do cone}

O ponto inicial da tarefa envolvendo o estudo do cone deu-se com a solicitação do professor-pesquisador para que os alunos consultassem a definição desse sólido no livro didático (DANTE, 2010). O referido material apresentou os procedimentos de construir do cone, os quais geraram dificuldades de compreensão aos alunos, por conta da utilização do vocabulário geométrico.

Segundo Dante (2010), o aluno devia considerar um plano $\alpha$, uma região circular $\mathrm{R}$ nesse plano e um ponto $\mathrm{P}$ não pertencente $\mathrm{a} \alpha$. A reunião de todos os segmentos que ligam cada ponto de $R$ ao ponto $P$ é um sólido chamado de cone circular (figura 69).

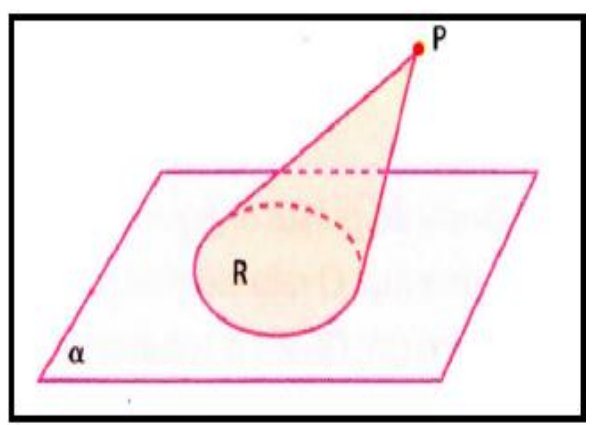

FIGURA 8: Construção de um Cone Fonte: Dante (2010, p.254)

Seguimos os procedimentos de construção do cone sugeridos por Dante (2010) utilizando o Geoespaço para que os alunos pudessem compreender o que caracteriza o cone:

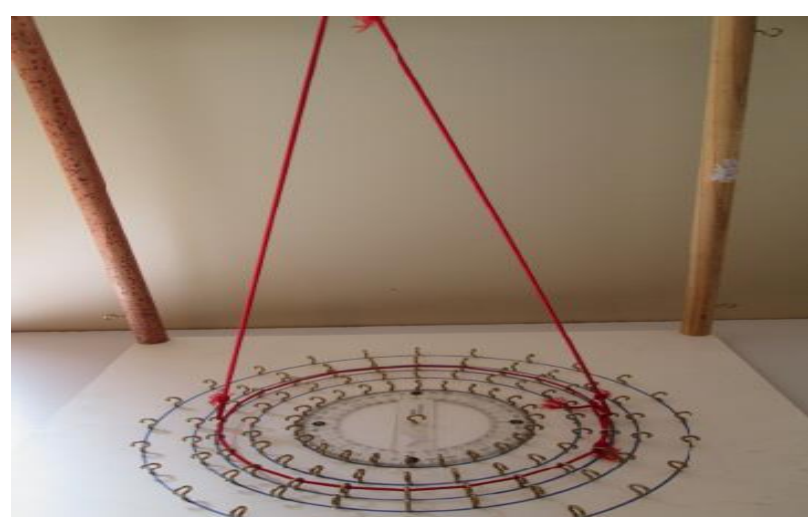

FIGURA 9: Construção de um Cone Fonte: arquivo do pesquisador 
A partir dessa construção no material manipulativo, foi pedido aos alunos que representassem a imagem da figura geométrica em questão. Foram obtidos as seguintes classes de desenhos:

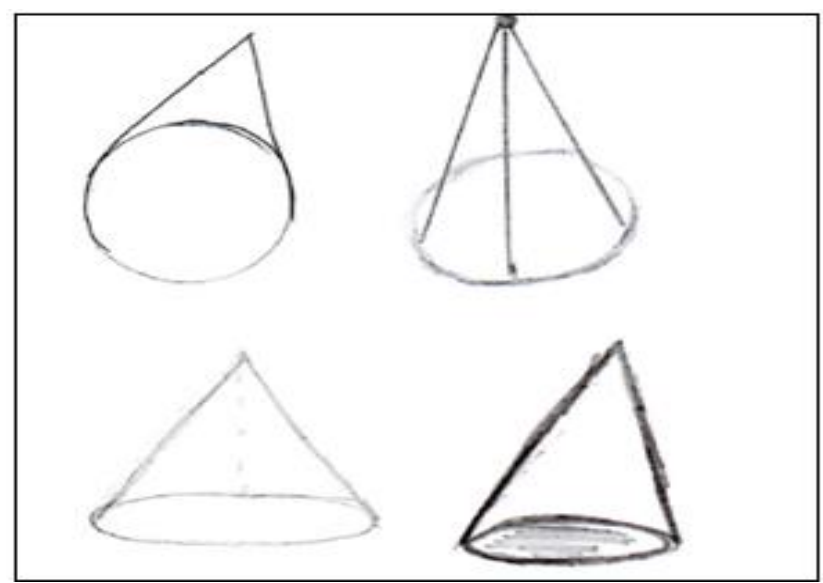

FIGURA 10: Desenhos do Cone

Fonte: arquivo do pesquisador

$\mathrm{Na}$ sequência o professor-pesquisador convidou seus alunos para confrontar suas representações com a imagem do cone contida no livro didático de Dante (2010):

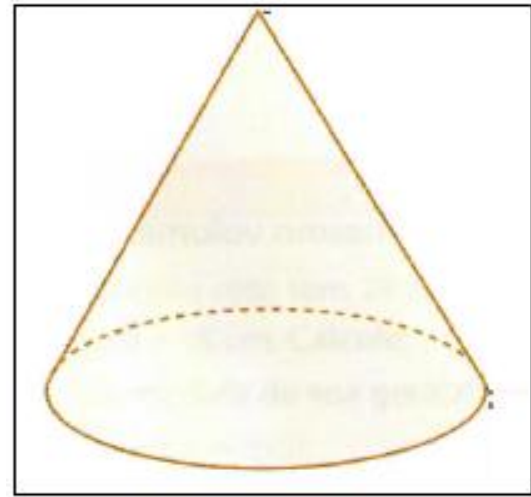

FIGURA 11: Representação do cone reto Fonte: Dante (2010, p.258)

Ao analisar a produção escrita dos alunos, os quais foram nomeados por letras do alfabeto, categorizamos suas respostas conforme tabela a seguir:

TABELA 1:Classificação das respostas dos vinte alunos

\begin{tabular}{|l|c|}
\hline \multicolumn{1}{|c|}{ Categorias de respostas } & Quantidade \\
\hline Respostas suficientemente argumentadas & 6 \\
\hline Respostas com justificativas implícitas & 7 \\
\hline Respostas sem justificativas & 4 \\
\hline Respostas confusas & 3 \\
\hline
\end{tabular}




\begin{tabular}{|l|l|}
\hline Ausências de respostas & 0 \\
\hline
\end{tabular}

Fonte: Arquivo do pesquisador

Apresentamos para o leitor a estratificação e análise parcial do conteúdo das respostas referente apenas à primeira categoria, a partir do quadro a seguir:

\begin{tabular}{|c|l|}
\hline Aluno & \multicolumn{1}{|c|}{ Resposta } \\
\hline A & $\begin{array}{l}\text { Não ficou parecido, não achatei o circulo e o vértice ficou muito } \\
\text { torto. }\end{array}$ \\
\hline B & $\begin{array}{l}\text { Não ficou igual, daí quis melhorar com mais uma reta, mas só } \\
\text { piorou. }\end{array}$ \\
\hline C & $\begin{array}{l}\text { Ficou muito parecido com o livro didático. A única diferença é } \\
\text { que não pontilhei a parte que fica escondida. }\end{array}$ \\
\hline D & $\begin{array}{l}\text { Ficou igual, e para ficar mais fácil de ver eu pintei a base do } \\
\text { cone. }\end{array}$ \\
\hline E & Ficou igual ao do livro, mas não pontilhei a base. \\
\hline F & $\begin{array}{l}\text { Ficou igual ao do livro, faltou apenas pontilhar a parte de trás da } \\
\text { base. }\end{array}$ \\
\hline
\end{tabular}

QUADRO 1: Respostas suficientemente argumentadas

Fonte: Arquivo do pesquisador.

No conteúdo da resposta do aluno A notamos a necessidade de adequar o vocabulário geométrico. No lugar de círculo, o correto é circunferência, além do fato de que 'achatar o círculo' diz respeito a imagem de uma figura geométrica que tais alunos não sabiam naquele momento qualificar de elipse. Nesse momento, o professor-pesquisador interviu e recorreu à lousa para marcar dois pontos distintos e com o auxilio de um cadarço de tênis cujo comprimento superou a distância entre esses dois pontos, foi possível obter uma elipse.

Em relação ao vértice, o professor-pesquisador apresentou para a turma o fragmento da frase 'o vértice ficou muito torto' para que juntos chegassem à interpretação correta de que o eixo (segmento de reta que liga o vértice ao centro da base do cone) não formou o ângulo de 90 graus e isto caracterizou o termo 'torto', no caso, um ângulo maior que 90 graus: 


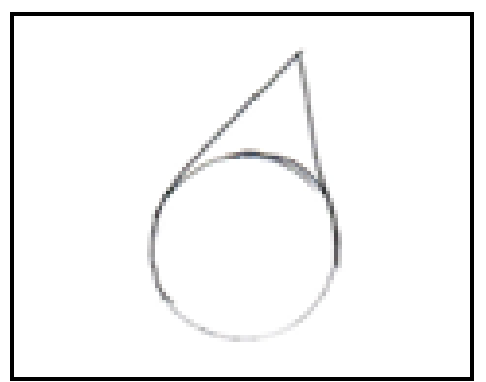

FIGURA 12: Desenho elaborado pelo aluno A Fonte: Arquivo do pesquisador.

No caso do aluno B, ao escrever que 'daí quis melhorar com mais uma reta, mas só piorou', o professor-pesquisador novamente convocou a turma para avaliar o porquê do termo 'piorou', junto ao conteúdo do seu desenho:

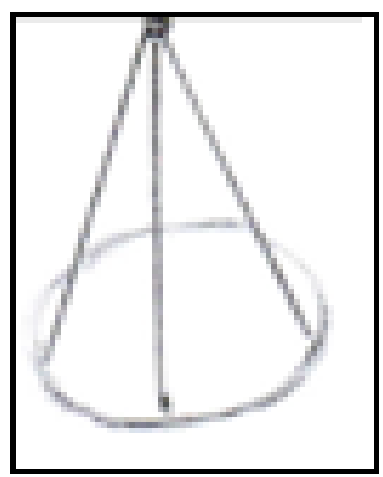

FIGURA 13: Desenho elaborado pelo aluno B Fonte: Arquivo do pesquisador.

Para auxiliar na compreensão sobre a questão proposta, o professorpesquisador convocou os alunos para pesquisarem sobre a definição de um cone, ausente no livro didático disponível aos alunos (DANTE, 2010). A partir da discussão sobre o significado de sólido de revolução, os alunos compreenderam em que sentido os segmentos de reta desenhados pelo aluno B comprometeram na representação da imagem do cone.

\section{Considerações finais}

A potencialidade capital do uso do Geoespaço foi romper com a ideia de que a imagem dos sólidos geométricos apresentadas nos livros didáticos é única. O confronto dos desenhos produzidos a partir da visualização dos sólidos geométricos representados no material manipulável com a imagem contida no 
livro didático (DANTE, 2010) propiciou aos alunos chegarem à constatação de que cada objeto geométrico possibilita diversas representações, dependendo do ponto de vista da pessoa que concebe a sua imagem mental.

No segundo momento do trabalho de campo, foram desenvolvidas tarefas exploratórias-investigativas segundo as ideias de Ponte (2009) e estas visavam à análise das propriedades dos sólidos geométricos. Tais tarefas incentivaram a participação ativa dos alunos no processo de ensino-aprendizagem e, no desenvolver delas, ficou evidente a aquisição de competências fundamentais no estudo da geometria, segundo o Currículo do Estado de São Paulo (SÃO PAULO, 2012). O desenvolvimento das capacidades de expressão, compreensão, argumentação e abstração, confirmando a teoria de Pais (1996) sobre a construção da abstração dos conceitos de generalidade pouco a pouco por influência do mundo físico. Os alunos foram aprimorando suas capacidades de abstrair e generalizar conforme manipulavam o geoespaço visando a resolução das tarefas propostas.

Vale destacar também o aperfeiçoamento do vocabulário geométrico, a medida os alunos desenvolveram a percepção de formas e de relações entre elementos de figuras planas e espaciais, a construção e a representação de formas geométricas e a elaboração de concepções de espaço. Tais competências servem de suporte para a compreensão do mundo físico, por meio de processos de experimentação.

É necessário frisar que, durante o trabalho com o material manipulável, o professor deve estar ciente do seu papel como educador, compreendendo os objetivos da matemática a serem alcançados e sendo capaz de criar situaçõesproblemas de ensino-aprendizagem. Mas não basta ao professor apenas conhecer a matéria, ele deve apresentá-la com clareza, tendo entusiasmo pelo trabalho de educador, sempre destacando o seu valor utilitário para a vida corrente, o seu valor formativo para o desenvolvimento do raciocínio lógico, o seu valor sociológico por sua universalidade e o seu valor estético por sua beleza. 
No entanto, o professor deve se lembrar de sempre de que o material manipulativo, no caso o Geoespaço pode não superar a categoria de 'meio' para o ensino de matemática, uma vez que a utilização deste tipo de material depende da concepção do professor a respeito da matemática e do seu ensinoaprendizagem. No decorrer da aula podem surgir conteúdos matemáticos não previstos para aquele momento, como foi o caso da abordagem da elipse no momento em que o aluno associou a imagem mental deste objeto geométrico com a ação de achatar o círculo.

Durante a pesquisa, compreendemos também a importância de preparar uma aula e escolher a metodologia adequada e como trabalhar com tarefas de representação figural segundo a teoria de Fischbein (1993) e com tarefas exploratório-investigativas no ensino da matemática segundo as ideias de Ponte (2009), pois estas levam tanto o aluno, como o professor a repensar o processo de ensino, pois tornam a aprendizagem mais ativa, incentivando o pensamento crítico e analítico. Descobrimos, nessa pesquisa, como é importante o trabalho referente às representações figurais, principalmente no ensino da geometria, pois essa parte fez com todos os envolvidos nesse processo viessem a elaborar questionamentos sobre o modo como fazemos tais representações figurais, e de como lidamos com as representações figurais impostas pelos livros didáticos.

O Geoespaço tem sido alvo de estudo e produção de outras tarefas no âmbito do GEPLAM, como o cálculo de troncos de diversos sólidos geométricos. Implantamos na base do Geoespaço circular o transferidor e isto ampliou o desenvolvimento de tarefas, pois temos a possibilidade de elaborar situaçõesproblemas envolvendo o cálculo do volume de secções no cilindro e no cone.

\section{Referências}

DANTE, L. R. Matemática: contexto e aplicações. 1ª Edição. São Paulo: Ática, 2010. 341 p.

FISCHBEIN, E. The teory of figural concepts. Educational Studies in Mathematics, Springer Netherlands, v.24, p. 139- 162, 1993. 
GRANDO, R. C.; NACARATO, A. M.; GONÇALVES, L. M. G. Compartilhando saberes em geometria: investigando e aprendendo com nossos alunos. Caderno Cedes, Campinas, v. 28, no 74, p. 39-56, 2008.

KUSUKI, L. R. Um estudo das potencialidades pedagógicas de atividades exploratórias-investigativas com o material didático Geoespaço. 2014. $213 \mathrm{f}$. Dissertação (Mestrado em Ensino de Ciências Exatas) - Universidade Federal de São Carlos, Sorocaba, 2014.

LORENZATO, S. O laboratório de ensino de matemática na formação de professores. Campinas: Autores Associados, 2006.178p.

MOREIRA, H. Critérios e estratégias para garantir o rigor na pesquisa qualitativa. Revista Brasileira de Ensino de Ciência e Tecnologia, Ponta Grossa, v.11, n.1, p.405-424, 2018.

NACARATO, A. M. Eu trabalho primeiro no concreto. Revista de Educação Matemática, São Paulo, v. 9, n. 9-10, p. 7-14, 2005.

PAIS, L. C. Intuição, experiência e teoria geométrica. Zetetiké, Campinas, v.4, n.6, p.6574, jul./dez., 1996.

PONTE, J. P.; BROCARDO, J.; OLIVEIRA, H. Investigações matemáticas na Sala de Aula. $2^{a}$ edição. Belo Horizonte: Autêntica, 2009. 158p.

SÃO PAULO. Secretaria da Educação. Currículo do Estado de São Paulo: Matemática e suas tecnologias - Ensino Fundamental (Ciclo II) e Ensino Médio. Coordenação de área: Nilson José Machado. $1^{\underline{a}}$ ed. atual. São Paulo, SEE, 2012. 72p 